\title{
Comunicando o conhecimento acadêmico além do texto acadêmico escrito: uma análise autoetnográfica do experimento da instalação Mirror Palace of Democracy ${ }^{1}$
}

Communicating academic knowledge beyond the written academic text; an autoethnographic analysis of the Mirror Palace of Democracy installation experiment

\author{
NICO CARPENTIERa \\ Charles University, Departamento de Estudos de Mídia. Praga, República Tcheca \\ Vrije Universiteit Brussel, Departamento de Ciências da Comunicação. Bruxelas, Bélgica \\ Uppsala Universitet, Departamento de Informática e Mídia. Uppsala, Suécia
}

\section{RESUMO}

$\mathrm{O}$ artigo discute inicialmente cinco abordagens que visam transcender, complementar ou desestabilizar a hegemonia do texto acadêmico escrito. Na segunda parte, o experimento da instalação Mirror Palace of Democracy, que tinha o objetivo explícito de ir além do texto acadêmico escrito, permanecendo no domínio da comunicação do conhecimento acadêmico, é analisada autoetnograficamente. A experiência permitiu refletir sobre o caráter integrado e iterativo da comunicação acadêmica, a identidade híbrida acadêmicoartística e a diversificação de públicos. Tanto a discussão teórica como a instalação Mirror Palace of Democracy fazem parte de um apelo a mais experimentação e teorização da comunicação acadêmica multimodal e/ou baseada nas artes.

Palavras-chave: Comunicação acadêmica, estudo acadêmico multimodal, pesquisa baseada nas artes, instalação artística, democracia

\begin{abstract}
The article first discusses five approaches that aim to transcend, complement, or overturn the hegemony of the written academic text. In the second part, the Mirror Palace of Democracy installation experiment, which had the explicit objective of moving beyond the written academic text while still remaining in the realm of academic knowledge communication, is autoethnographically analyzed. The experiment allowed reflection on the integrated and iterative nature of academic communication, on the hybrid academicartistic identity, and on the diversification of publics. Both the theoretical discussion and the Mirror Palace of Democracy installation are part of a call for more experimentation with, and theorization of, multimodal and/or arts-based academic communication.
\end{abstract}

Keywords: Academic communication, multimodal scholarship, arts-based research, installation art, democracy

\author{
${ }^{1}$ Artigo originalmente \\ publicado no International \\ Journal of Communication, \\ 14(20). \\ ${ }^{a}$ Professor extraordinário \\ na Charles University em \\ Praga; também ocupa cargos \\ de meio período na Vrije \\ Universiteit Brussel, como \\ professor associado, e na \\ Uppsala Universitet, como \\ pesquisador sênior. E-mail: \\ nico.carpentier@fsv.cuni.cz. \\ Orcid: https://orcid.org/0000- \\ 0002-8996-4636
}




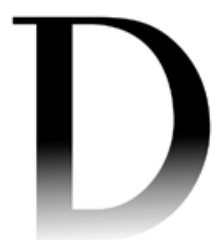

${ }^{2}$ Vários conceitos estão sendo usados nessas discussões: Reid et al. (2016) referem-se ao texto escrito como o "texto alfabético"; Murray (2009) escreve sobre a "hegemonia do texto discursivo" (p. 8). Literat et al. (2018) usam formatos acadêmicos "baseados em texto" e "baseados em papel". Aqui, o conceito de "texto escrito" é considerado o mais adequado, tendo em vista que o conceito de "texto" é definido em um sentido amplo para "incluir todas as formas de mediação na linguagem, som, odor e imagem" (Lewis, 2008, p. 5).

${ }^{3}$ É claro, os textos escritos muitas vezes contêm outros modos comunicativos (ver

Elkins, 2007), e também o modo oral é frequentemente usado, por exemplo, nas apresentações em conferências.

${ }^{4}$ Experimento é utilizado aqui no entendimento de senso comum, referindo-se a uma situação em que me engajei em uma (para mim) nova atividade, com o objetivo de estimular a aprendizagem e a inovação.
$\mathrm{N}$ A COMUNICAÇÃO ACADÊMICA, o texto escrito ${ }^{2}$ possui uma posição hegemônica. Além de onipresente na academia e crucial para o desempenho da identidade acadêmica (Ivanič, 1998), devemos ter em mente que a escrita acadêmica também é um gênero específico (Bazerman, 1988, p. 8). Essa (admissão da) particularidade tem uma série de implicações. É crucial o fato de a escrita acadêmica não ser capaz de absorver e representar todo o conhecimento: "As formulações científicas são uma construção humana e, portanto, herdeiras de todas as limitações da humanidade", como escreve Bazerman (1988, p. 294). Isso então abre caminho para o argumento de que, como nenhuma hegemonia é total (Mouffe, 2005, p. 18), outras formas (ou modos) de comunicar o conhecimento acadêmico ainda são possíveis e até desejáveis ${ }^{3}$. A particularidade de cada modo também produz oportunidades para a comunicação do conhecimento, já que cada forma particular tem suas próprias possibilidades (affordances) (Gibson, 1979; Norman, 1988) e sua combinação pode enriquecer a academia, porque, como notam Literat et al. (2018) sobre o conhecimento multimodal, "possui potencial para investigações, análises e representações mais abrangentes e inclusivas que podem ser social, cultural e politicamente transformadoras" (p. 569).

Este artigo relata um experimento ${ }^{4}$ particular, em que a instalação artística Mirror Palace of Democracy (MPD) foi utilizada para comunicar uma reflexão teórica sobre a contingência da democracia em relação à mídia, à representação e à participação. Esta experiência não teve como objetivo desacreditar a escrita acadêmica, mas sim investigar a capacidade do formato (gênero da) instalação de arte de comunicar o conhecimento acadêmico. Como experimento, foi informado por cinco conjuntos de literatura - alguns autônomos, outros afiliados a disciplinas particulares -, que, cada um à sua maneira, confrontam a hegemonia do texto acadêmico escrito. Essas abordagens são brevemente discutidas na primeira parte deste artigo e, em seguida, sintetizadas em uma visão geral. A segunda parte do artigo relata a análise autoetnográfica do experimento da instalação do $M P D$. Esta análise é estruturada e apoiada por três dimensões-chave que caracterizam as cinco abordagens e que foram desenvolvidas por meio de uma série de iterações de fertilização cruzada entre a revisão da literatura e a análise autoetnográfica. A discussão mais detalhada dessas três dimensões - a natureza da produção do conhecimento, as posições dos sujeitos e as relações com os públicos - é, assim, reservada para a segunda parte do artigo.

Além dessas reflexões teóricas sobre o texto acadêmico não escrito e da análise do experimento do $M P D$, este artigo também é motivado por um forte apelo para a reflexão sobre o uso mais amplo de textos acadêmicos não escritos nos estudos de mídia e comunicação, nos quais isso ainda é raro. Claro, 
vários outros acadêmicos argumentaram antes a favor da pesquisa acadêmica multimodal e/ou baseada nas artes (mídia e comunicação) (ver, por exemplo, McPherson, 2009, no contexto das humanidades digitais). E alguns a realizam 5 . Às vezes, isso é feito de formas mais modestas, por exemplo, nas palestras TED e TEDx ${ }^{6}$ ou pelo envolvimento em atividades de troca de conhecimento (ver Freeman, 2016). E em outros casos, mais estruturais, como, por exemplo, o trabalho do Coletivo para o Desenvolvimento da Pesquisa de Artes Multimodal (https://www.camrapenn.org/) ou dos acadêmicos do Departamento de Estudos da Comunicação da Concordia University (Chapman \& Sawchuk, 2015). Os estudiosos da comunicação e dos estudos de mídia também publicam seus textos não escritos em revistas especializadas como o Journal of Video Ethnography; Tecmerin: Journal of Audiovisual Essays; e Audiovisual Thinking, the Journal of Academic Videos. Além disso, tanto a Associação Internacional de Comunicação quanto a Associação Internacional de Pesquisa de Mídia e Comunicação apresentaram exposições em algumas de suas conferências recentes, a primeira com a mostra Making \& Doing (https://bit.ly/359BC7N) ${ }^{7}$, de 2017, e a posterior, de 2018, com o Ecomedia Arts Festival (https://oregon2018.iamcr.org/ecomedia), dando pequenos passos em direção a (ao reconhecimento de) textos acadêmicos não escritos. Entretanto, muito mais poderia ser feito em nosso campo para teorizar essas práticas e implementá-las. Assim, este texto também pretende funcionar como uma introdução informada e informativa.

\section{A ACADEMIA E O TEXTO NÃO ESCRITO}

Ainda que o texto escrito seja o modo central de comunicação do conhecimento acadêmico, existem várias abordagens que desafiam essas "concepções hegemônicas sobre modos legítimos de investigação, análise e representação acadêmicas" (Literat et al., 2018, p. 566). Essas visam transcender, complementar ou desestabilizar essa hegemonia. Com base em uma extensa revisão da literatura narrativa, identifiquei cinco abordagens. As duas primeiras - os agrupamentos de (1) comunicação científica, popularização científica e disseminação do conhecimento; e (2) troca de conhecimento e pesquisa (ação) participativa, transformativa e de intervenção - são relativamente autônomas. Alguns argumentaram (por exemplo, Trench \& Bucchi, 2010) que são, na verdade, disciplinas (emergentes) em seu próprio direito. As três outras abordagens estão mais inseridas em disciplinas específicas - a saber, estudos da escrita, antropologia, sociologia e artes - embora também tenham se espalhado para outras arenas disciplinares.
${ }^{5}$ Esses exemplos são evidenciados de acordo com as cinco abordagens que serão discutidas posteriormente.

${ }^{6}$ Ver, por exemplo a fala de Sonia Livingstone no TEDxExeter: https://bit. ly/339jNUq

${ }^{7} \mathrm{O}$ livro temático da conferência Associação Internacional de Comunicação, de 2017 (sobre intervenções), também tem um capítulo sobre a exposição (Henderson et al., 2018). 
A primeira abordagem é a do grupo da comunicação científica, popularização da ciência e disseminação do conhecimento, a qual não tenta, propriamente, oferecer ferramentas acadêmicas alternativas para a comunicação, mas visa traduzir trabalhos acadêmicos existentes (e publicações) em outros textos que usam repertórios linguísticos calibrados para um leitor não acadêmico, de modo a democratizar a recepção do conhecimento acadêmico. Ao mesmo tempo, essa abordagem está preocupada com a compreensão e a consciência da ciência como um todo (Burns et al., 2003). A definição de Bryant (2003) de comunicação científica como "os processos pelos quais a cultura científica e seu conhecimento se incorporam à cultura comum” (p. 357) é ilustrativa desse foco no campo acadêmico como um todo, ainda que os exemplos sejam menções em seu artigo - referindo-se, por exemplo, ao momento em que "a televisão ABC estava filmando uma notícia” sobre a pesquisa de Bryant (2003, p. 357) - indicativas da importância do nível micro, com a comunicação a respeito do trabalho de pesquisadores individuais.

O exemplo de Bryant (2003) também indica a importância da mídia (de massa) dentro desta abordagem, uma vez que essa atua como mediadora e comunicadora, ou "agente de conhecimento" (ver Meyer, 2010). Por exemplo, a visão geral de Kara (2015, p. 161) das estratégias de disseminação de conhecimento, as quais têm o "objetivo último" de permitir que "sua pesquisa e suas descobertas ganhem vida própria e sejam disseminadas por outras pessoas, que falem e escrevam sobre o seu trabalho" (p. 177), aborda de forma explícita e extensiva o papel da mídia convencional em combinação com blogs, podcasts e mídia social (ver também Müllerleile, 2014). Uma das consequências dessa ênfase no papel dos mediadores externos é que a identidade do acadêmico - ou, na terminologia de Laclau e Mouffe (1985, p. 115): a posição de sujeito do acadêmico permanece articulada de maneiras mais tradicionais. Além disso, mesmo que a produção de textos não escritos, ou de textos escritos de forma diferente, seja um componente significativo dessa abordagem, esses textos tendem a ser vistos como publicações de segundo estágio ou post-ante, precedidas por textos acadêmicos escritos e então traduzidos em textos novos (e mais acessíveis) para públicos que, no entanto, permanecem desconectados do próprio processo de produção do conhecimento.

Uma segunda abordagem, que responde à primeira e, portanto, está relacionada a ela, é o grupo da troca de conhecimento e da pesquisa (ação) participativa, transformadora e de intervenção. Kara (2015) define a troca de conhecimento como "uma abordagem mais igualitária que implica um processo bidirecional de compartilhamento de conhecimento entre pesquisadores, profissionais, usuários do serviço e outras pessoas interessadas” (p. 176). Também as abordagens mais 
intervencionistas (por exemplo, a pesquisa-ação participativa; ver Fals-Borda \& Rahman, 1991; Reason \& Bradbury, 2001), que têm o objetivo mais explícito de impactar realidades sociais específicas e contribuir para a mudança social, colocam ênfase significativa na troca de conhecimento e na partilha com o objetivo de democratizar a própria produção do conhecimento.

Essa abordagem (ou conjunto de abordagens) de troca/colaborativa/participativa torna-se significativa no contexto dessa análise por duas razões, mesmo que nem sempre (defendam e) usem textos acadêmicos não escritos. Primeiro, são caracterizadas por alterar o equilíbrio de poder entre acadêmicos e não acadêmicos, redefinindo a posição de sujeito do acadêmico, cuja voz não é mais vista como privilegiada. Essa abordagem vai de encontro à ideia de que o conhecimento flui linearmente da academia para os outros campos (Blundell, 2017, p. 308), característica que compartilha com outras abordagens, por exemplo, a etnografia multivocal e polifônica (Tyler, 1986) e com (em certa medida) as pesquisas baseadas nas artes, às quais retornarei posteriormente. Aqui, a ênfase na mudança social produz posições de sujeito acadêmico mais híbridas, por exemplo, por meio da integração de posições de sujeito acadêmico e ativista (Routledge, 1996, p. 405). Em segundo lugar, a dimensão colaborativa/ participativa necessita do desenvolvimento e uso de ferramentas e formatos comunicacionais que apoiem esses diálogos, possibilitando essas formas mais dialógicas de criação de conhecimento (Matschke et al., 2012; H. Mitchell, 2006; Murdock et al., 2013; Unicef, 2015). O artigo de Moncaster e colegas (2010, p. 170), que contém um inquérito sobre ferramentas de aquisição de conhecimento da indústria, é uma das poucas publicações nessa área que também se refere a ferramentas audiovisuais (nomeadamente, programas de televisão e filmes). A maioria dessas publicações enfatiza a importância das ferramentas comunicativas para a troca de conhecimento, mas muitas vezes se restringem a textos escritos em combinação com a comunicação oral (informal).

As outras três abordagens estão inseridas em disciplinas específicas e se concentram mais explicitamente em combater a hegemonia do texto acadêmico escrito, oferecendo espaço para textos não escritos e reconhecendo a natureza iterativa da produção de conhecimento. Eles também compartilham o objetivo de expandir suas fronteiras disciplinares, tanto no nível de suas práticas comunicativas quanto dos (potenciais) públicos que (podem) atingir. A terceira abordagem é a comunicação acadêmica multimodal, particularmente presente no campo da composição ${ }^{8}$ (situado na área mais ampla dos estudos da escrita), com, por exemplo, livros como Multimodal composition: Resources for teachers (Selfe, 2007), Toward a composition made whole (Shipka, 2011), Multimodal composition (Lutkewitte, 2013) e Bridging the multimodal gap (Khadka \& Lee,
${ }^{8}$ As práticas acadêmicas multimodais são muito mais antigas e difundidas que o próprio rótulo, o que é evidenciado pela importância da ilustração científica (ver, por exemplo, Ford, 1992); entretanto, essas práticas foram além do campo dos estudos da escrita. 
2019). A inspiração conceitual para essa abordagem vem da teoria multimodal, que (obviamente) não enfoca de maneira explícita a comunicação acadêmica. A multimodalidade, nesse sentido amplo, refere-se ao "uso de vários modos semióticos no design de um produto ou evento semiótico, juntamente com a forma particular como esses modos são combinados" (Kress \& Van Leeuwen, 2001, p. 20), mas essa ampla conceituação é então empregada para teorizar a comunicação acadêmica multimodal.

Essa abordagem multimodal argumenta, de forma explícita, nas palavras de Murray (2009), que o desafio "não é de substituição, mas de adição" (p. 8). Ela defende o texto escrito "com suas estruturas sequenciais, expectativas disciplinares e, em última instância, tom distante", mas também dá apoio à necessidade de complementá-lo com o que chama de "textos não discursivos", "com suas camadas, imagens e, sem dúvida, afetividade difusa" (p. 8). Parte da argumentação utilizada por essa abordagem está baseada na ideia de que a comunicação acadêmica nunca foi, e não pode ser, restrita a textos escritos (Lemke, 1998, p. 87), mas, ao mesmo tempo, a abordagem da comunicação acadêmica multimodal ainda explica a importância dos textos não escritos e amplia seu uso na comunicação acadêmica, expandindo, assim, a posição de sujeito acadêmico para além de escritor acadêmico. Ainda assim, embora o texto não escrito possa ser "visual, tátil, aural, olfativo e gustativo" (Murray, 2009, p. 8), na prática, muitas vezes encontramos nesta abordagem um forte foco em "textos que incorporam palavras, imagens, vídeo e som" (Takayoshi \& Selfe, 2007, p. 3; ver Thorndike-Breeze et al., 2019, para o uso de quadrinhos) impulsionados pelas possibilidades do on-line.

Uma quarta abordagem, que também lida com a hegemonia do texto escrito, pode ser encontrada no agrupamento da antropologia visual e da sociologia visual, que têm uma longa tradição em expandir suas práticas comunicativas acadêmicas, articulando texto escrito, fotografia e filme. Mas devemos também ter em mente que, antes do rótulo visual ser combinado com a antropologia, antropólogos importantes como Margaret Mead (1995) já integravam a fotografia e o texto escrito, fundamentados em uma crítica à antropologia como uma "disciplina de palavras". Um exemplo é a colaboração de Mead com Bateson, que resultou no livro, de 1942, Balinese character: A photographic analysis

${ }^{9}$ Além disso, a integração de elementos literários na escrita antropológica foi utilizada e defendida, entre outros, por Geertz. Como Barone (2008) resume, Geertz "descreveu e defendeu as qualidades poéticas e narrativas da etnografia" (p. 107). (Bateson \& Mead, 1942)9. Quando nos concentramos mais na antropologia visual, podemos encontrar, por exemplo, em Principles of visual anthropology, de Hockings (1995) - originalmente publicado em 1975 -, o registro da importância (e da longa história) dos filmes etnográficos. Mesmo que Hockings ainda se preocupe com a capacidade do filme de comunicar conhecimento acadêmico, trabalhos posteriores em antropologia visual reconhecem mais claramente o 
uso da fotografia e do filme para "transmitir resultados de pesquisas" (Holm, 2008, p. 326), argumentando que esses modos comunicativos podem "estar envolvidos nos processos por meio dos quais o conhecimento etnográfico é criado e representado" (Pink, 2004, p. 1). Essas práticas também se traduziram na consolidação de revistas científicas especializadas, como, por exemplo, o Journal of Video Ethnography, que visa "promover o uso científico social do vídeo/filme como um método para explorar a sociedade, os sistemas e as culturas humanas e como um meio para apresentar os resultados dessas explorações" (http://www.videoethno.com/).

Embora a sociologia visual esteja ainda mais voltada para a análise do visual (Holm, 2008, p. 327), vários autores têm defendido o uso da visualidade para comunicar o conhecimento acadêmico. Em seu artigo "The scope of visual sociology", Grady (1996) $\operatorname{argumenta}{ }^{10}$ que a proliferação de novas tecnologias "criou novos modos de representação da informação, bem como meios inteiramente novos para comunicar os resultados da pesquisa" (p. 10). Chaplin (1994) apresenta um argumento semelhante em seu livro Sociology and visual representation, criticando o fato de que "tendemos a tomar como certa a preeminência do texto escrito em quase todas as áreas do conhecimento e a considerar qualquer material visual que o acompanha como subsidiário" (p. 3). Ela não apenas argumenta que "a análise social está começando a fazer mais uso da representação visual", mas também que "deve fazer mais uso de representações visuais, tipografia não convencional e layout de página em suas análises” (p. 2).

A quinta e última abordagem discutida aqui é a pesquisa baseada nas $\operatorname{artes}^{11}$. A pesquisa baseada em artes é mais específica do que a pesquisa artística (Klein, 2017), embora esteja relacionada. Como Leavy (2015) escreve, a pesquisa baseada em artes ${ }^{12}$ é "um conjunto de ferramentas metodológicas usadas por pesquisadores em todas as disciplinas durante todas as fases da pesquisa social, incluindo geração, análise, interpretação e representação de dados" (p. ix, destaque no original). Ainda enraizada na academia, consiste na busca por diferentes formas de divulgação para comunicar o conhecimento acadêmico, ou, para usar as palavras de Leavy, "desenvolve conversações críticas sobre a natureza da prática social científica e expande as fronteiras de nosso repositório de métodos" (p. 11). A afirmação de Leavy $(2015$, p. 11, 19, 294) de que a pesquisa baseada nas artes é um paradigma alternativo, distinto dos paradigmas quantitativos e qualitativos, pode soar um pouco excessiva, mas, ao mesmo tempo, deve- se reconhecer que o foco na ressonância e evocação (Leavy, 2015, p. 294) dá singularidade a esse tipo de pesquisa. Além disso, sua ênfase no fazer (criar) traz a ideia de que o conhecimento é ou - dito de forma mais modesta - pode ser corporificado e produzido por meio da criação da própria prática artística. Para
${ }^{10}$ Um gênero concreto que Grady (1996, p. 18) sugere é o ensaio visual. Um argumento semelhante poderia utilizado para o filme ensaio, que é discutido por Alter (2018, p. 5) como "filosofia filmada".

${ }^{11}$ Indiscutivelmente, a pesquisa baseada nas artes poderia ser estendida à pesquisa baseada na prática, mas isso está além do escopo deste artigo. Além disso, diferentes rótulos para pesquisas baseadas em artes têm sido usados. Por exemplo, no Canadá, o termo pesquisacriação é com frequência utilizado (ver, por exemplo, Loveless, 2015).

${ }^{12} \mathrm{~A}$ pesquisa baseada nas artes não é o único projeto intelectual que visa integrar mais repertórios artísticos à academia. Por exemplo, a fictocrítica, um conjunto de projetos (principalmente) feministas, que procura combinar a escrita ficcional, a teoria e a crítica (Gibbs, 2003; Haas, 2017). Mas a pesquisa baseada nas artes é particularmente relevante aqui devido a seu afastamento do texto escrito. 
usar a formulação mais poética de Cooperman (2018), "a pesquisa baseada em artes é uma pesquisa da carne, na qual a fonte de nosso material se origina da proximidade e colaboração dos corpos e vozes uns dos outros” (p. 22).

No entanto, o uso de repertórios artísticos comunicacionais pela pesquisa baseada em artes ainda implica parcialmente o uso de textos escritos para comunicar conhecimento (acadêmico). Um exemplo seminal é o romance Low-fat love, de Leavy (2011), que usa um formato ficcional para comunicar pesquisas (baseadas em entrevistas) sobre os relacionamentos das mulheres com seus parceiros, parentes e com seu próprio corpo. Além disso, a riqueza de repertórios comunicacionais artísticos permite o uso de uma variedade de ferramentas comunicacionais não escritas muito distintas. A visão geral de Leavy (2015) dá uma primeira ideia das possibilidades:

As formas representacionais incluem, mas não estão limitadas a contos, romances, formas de escrita experimental, graphic novels, quadrinhos, poemas, parábolas, colagens, pinturas, desenhos, escultura, arte 3-D, colchas e bordados, roteiros de performance, apresentações teatrais, danças, filmes, canções e partituras musicais. (p. ix)

São muitos os exemplos possíveis, desde o etnodrama e o etnoteatro (Saldaña, 2005,2011 ) que, respectivamente, traduzem os resultados da pesquisa em um roteiro dramático e geram desde uma peça ao vivo com base nele a uma instalação artística (Lapum, 2018).

As cinco abordagens podem ser resumidas, como mostra a Tabela 1, mas deve-se notar, de saída, que esta visão geral é fatalmente limitada, não apenas em razão da impossibilidade de se fazer justiça à complexidade (e contradições internas) de cada uma dessas cinco abordagens, mas também devido à sobreposição entre elas. Por exemplo, Kara (2015), que tem como foco a disseminação do conhecimento, tem uma extensa discussão sobre o uso de repertórios artísticos para a divulgação acadêmica. Ela lista muitos exemplos, dos quais vários poderiam ser igualmente discutidos como exemplos de pesquisa baseada em artes. Outro exemplo é a mudança de nome da seção de antropologia visual em American Anthropologist. O novo nome, antropologia multimodal, foi fundamentado pelos editores de seção nas "mudanças nas ecologias de mídia em que nos engajamos como antropólogos, mudanças que ampliaram nossa perspectiva para incluir outras formas de práticas de mídia, embora com a permanência das da antropologia visual" (Collins et al., 2017, p. 142).

Uma das áreas mais interessantes em que a sobreposição se torna bastante tangível está relacionada às práticas participativas. Neste artigo, a pesquisa 
participativa já foi discutida como parte da abordagem da troca de conhecimento, mas alguns autores que escrevem sobre as pesquisas baseadas em artes argumentam que a participação é a chave para a última abordagem também, enfatizando as oportunidades de produção conjunta de conhecimento: "No cerne da investigação baseada nas artes está uma proposta radical e politicamente fundamentada sobre a justiça social e o controle sobre a produção e a disseminação de conhecimento" (Finley, 2008, p. 72). Outros consideram os métodos participativos baseados em artes (visuais), com os "participantes de pesquisa criando arte que, em última análise, serve como dados e também pode representar os dados" (Leavy, 2015, p. 232), como um subconjunto da pesquisa baseada na arte ou considerá-los como duas tradições separadas que podem ser combinadas (Gutberlet et al., 2017). Nesse sentido, é, por exemplo, notável como o gênero/método photovoice - "a combinação de fotografias e narrativas criadas pelo participante" (Jarldorn, 2019, p. 1) - possui características de muitas das abordagens discutidas.

Tabela 1. Panorama das cinco abordagens

\begin{tabular}{|c|c|c|c|c|c|c|}
\hline Abordagem & Objetivo & $\begin{array}{l}\text { Relação com } \\
\text { disciplina(s) } \\
\text { acadêmica(s) }\end{array}$ & $\begin{array}{l}\text { Modo(s) } \\
\text { Dominante(s) }\end{array}$ & $\begin{array}{l}\text { Relação com } \\
\text { público(s) }\end{array}$ & $\begin{array}{l}\text { Posição(ões) } \\
\text { de sujeito }\end{array}$ & $\begin{array}{l}\text { Produção de } \\
\text { conhecimento }\end{array}$ \\
\hline $\begin{array}{l}\text { Comunicação } \\
\text { científica, po- } \\
\text { pularização da } \\
\text { ciência e dis- } \\
\text { seminação do } \\
\text { conhecimento }\end{array}$ & $\begin{array}{l}\text { Demo- } \\
\text { cratizar a } \\
\text { recepção } \\
\text { do conheci- } \\
\text { mento }\end{array}$ & Post-ante & $\begin{array}{l}\text { Mídia } \\
\text { (massiva) }\end{array}$ & $\begin{array}{l}\text { Grupo-alvo } \\
\text { desconectado }\end{array}$ & $\begin{array}{l}\text { Acadêmicos } \\
\text { tradicionais } \\
\text { trabalhando } \\
\text { com agentes } \\
\text { de conheci- } \\
\text { mento }\end{array}$ & $\begin{array}{l}\text { Dois estágios } \\
\text { lineares }\end{array}$ \\
\hline $\begin{array}{l}\text { Troca de co- } \\
\text { nhecimento e } \\
\text { pesquisa (ação) } \\
\text { participativa, } \\
\text { transformativa } \\
\text { e de interven- } \\
\text { ção }\end{array}$ & $\begin{array}{l}\text { Demo- } \\
\text { cratizar a } \\
\text { produção } \\
\text { de conheci- } \\
\text { mento }\end{array}$ & $\begin{array}{l}\text { Em múltiplas } \\
\text { disciplinas }\end{array}$ & $\begin{array}{l}\text { Formatos } \\
\text { dialógicos } \\
\text { (domínio } \\
\text { do oral e do } \\
\text { escrito) }\end{array}$ & $\begin{array}{l}\text { Produção } \\
\text { conjunta de } \\
\text { conheci- } \\
\text { mento }\end{array}$ & $\begin{array}{l}\text { Hibridização } \\
\text { da posição } \\
\text { de sujeito } \\
\text { acadêmico }\end{array}$ & Dialógica \\
\hline $\begin{array}{l}\text { Comunicação } \\
\text { acadêmica mul- } \\
\text { timodal }\end{array}$ & $\begin{array}{l}\text { Expandir a } \\
\text { escrita }\end{array}$ & $\begin{array}{l}\text { Em estudos } \\
\text { de escrita (e } \\
\text { além) }\end{array}$ & $\begin{array}{l}\text { Audiovisual e } \\
\text { on-line }\end{array}$ & $\begin{array}{l}\text { Expansão de } \\
\text { públicos }\end{array}$ & $\begin{array}{l}\text { Posição } \\
\text { pós-escrita } \\
\text { de sujeito } \\
\text { acadêmico }\end{array}$ & Iterativa \\
\hline $\begin{array}{l}\text { Antropologia } \\
\text { visual e socio- } \\
\text { logia visual }\end{array}$ & $\begin{array}{l}\text { Expandir a } \\
\text { escrita an- } \\
\text { tropológica }\end{array}$ & $\begin{array}{l}\text { Na antro- } \\
\text { pologia e } \\
\text { sociologia }\end{array}$ & $\begin{array}{l}\text { Filme e } \\
\text { fotografia }\end{array}$ & $\begin{array}{l}\text { Expansão de } \\
\text { públicos }\end{array}$ & $\begin{array}{l}\text { Posição } \\
\text { pós-escrita } \\
\text { de sujeito } \\
\text { acadêmico }\end{array}$ & Iterativa \\
\hline $\begin{array}{l}\text { Pesquisa } \\
\text { baseada em } \\
\text { artes }\end{array}$ & $\begin{array}{l}\text { Expandir a } \\
\text { produção e } \\
\text { comunica- } \\
\text { ção de co- } \\
\text { nhecimento }\end{array}$ & $\begin{array}{l}\text { Combinando } \\
\text { as artes } \\
\text { com várias } \\
\text { disciplinas }\end{array}$ & $\begin{array}{l}\text { Repertórios } \\
\text { artísticos }\end{array}$ & $\begin{array}{l}\text { Expansão de } \\
\text { públicos }\end{array}$ & $\begin{array}{l}\text { Hibridização } \\
\text { da posição } \\
\text { de sujeito } \\
\text { acadêmico }\end{array}$ & Iterativa \\
\hline
\end{tabular}


${ }^{13}$ Ver Carpentier (2017, p. 4), Guattari (1993, p. 14) e DeLanda (2006, p. 12) adicionalmente.

${ }^{14} \mathrm{~A}$ especificidade de uma instalação como agenciamento discursivo e material torna impossível capturá-la integralmente neste artigo (ou em um filme, ou de qualquer outro modo). Mesmo que esse também seja o foco deste artigo, isso complica a visualização do MPD neste artigo. Além disso, a especificidade da instalação do MPD na exposição Respublika! impossibilitou a reflexão sobre a hegemonia do texto acadêmico escrito, que afetou a experiência dos visitantes.

\section{O MIRROR PALACE OF DEMOCRACY}

O MPD é uma instalação de arte (ver Bishop, 2005, para um esclarecimento e discussão crítica sobre a instalação de arte) que fez parte do festival de artes Respublika!, que aconteceu entre 4 de novembro de 2017 e 19 de janeiro de 2018, no Chipre. A curadoria do Respublika! foi feita por mim e ele foi organizado em colaboração com o centro de artes NeMe e o Cyprus Community Media Center. A instalação MPD foi uma das 17 obras de arte da exposição Participation Matters do Respublika!. Também foi criado por mim como uma reflexão teórica, mas ao mesmo tempo como um experimento para transcender o texto acadêmico escrito.

$\mathrm{O} M P D$ foi um agenciamento (assemblage $)^{13}$, uma materialização e simbolização ${ }^{14}$ simultâneas da contingência da democracia como um espaço de luta ideológica permanente sobre seu próprio significado e natureza, bastante influenciado pela teoria do discurso de Laclau e Mouffe (1985). Foi também um agenciamento que refletiu sobre como diferentes ideologias se engajam em uma luta política, oferecendo variados e, por vezes, contraditórios pontos de identificação aos cidadãos, que são comunicados por meio de uma variedade de mídias, com sua frequentemente forte ênfase na personalização (Bennett, 2012) e na visualidade (Veneti et al., 2019). Por fim, o MPD pretendia comunicar como essa luta ideológica pelos corações e mentes dos cidadãos é também uma luta corporificada, inscrita no corpo político em formas sempre únicas, mas ainda inescapáveis.

Para comunicar esse modelo teórico-discursivo de democracia, o $M P D$ utilizou o conceito de casa de espelhos, atração tradicional em parques e feiras de diversão. A casa de espelhos consiste em um labirinto, nesse caso construído com painéis de acrílico transparente, painéis de melamina não transparentes e espelhos (ver Figura 1). A casa dos espelhos pode ser vista, em si mesma, como uma metáfora da democracia, pois posiciona os visitantes em um labirinto que não foi criado por eles (delegando poder a um criador), mas que exige ações por parte deles para operar. Os espelhos da instalação também mostram os indivíduos, mas os replicam, produzindo uma coletividade visual - um povo de uma pessoa. Ao mesmo tempo, os espelhos do palácio complicam a noção de representação, criando reflexos quase infinitos, que produzem diversidade e mudança. Na casa dos espelhos, a representação é necessariamente instável. 


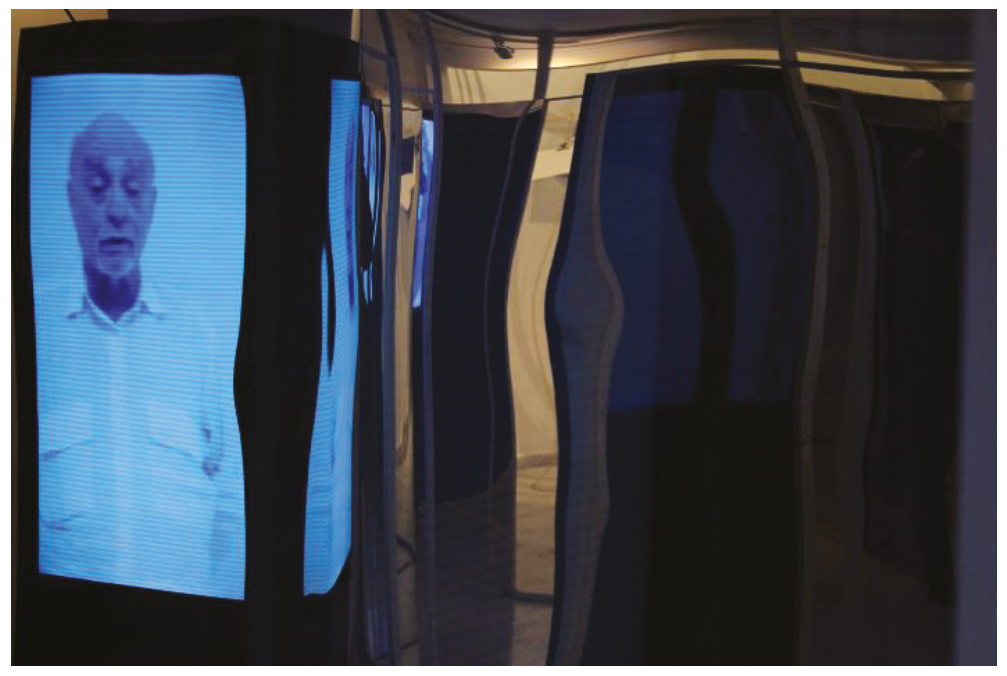

Figura 1

Foto do interior do Mirror Palace of Democracy

Nota. Foto do autor.

O MPD adiciona uma dimensão a este jogo com representação e participação ao trazer cinco vozes ideológicas que falam em nome do "povo" e representam a reivindicação que as ideologias têm sobre "o povo" (ver Carpentier, 2019 , p. 153, para as transcrições). Cada voz - representada por um ator que aparecia em uma imensa tela de TV - fala explicitamente em nome do "povo" por meio da repetição da frase: "Eu sou o povo". Eles convidam os visitantes a se identificarem com suas vozes solidárias, liberalistas, militaristas, autoritárias e nacionalistas, mas o palácio também incorpora materialmente (e aprisiona) os visitantes nessas vozes.

Ao mesmo tempo, as cinco vozes e suas reivindicações ideológicas tomadas em conjunto são contraditórias, significando que a democracia pode (e deve) acomodar e se basear na diversidade. Todas as cinco vozes reivindicam homogeneidade e estabilidade, mas sua justaposição significa simultaneamente a heterogeneidade e a contingência da democracia. Além disso, alguns dos projetos ideológicos selecionados também significam os limites do sistema democrático e as ameaças que determinadas ideologias representam para ele, indicando a noção de que a democracia nunca é dada e completa. Todos os cinco projetos ideológicos são comunicados por um indivíduo específico, semelhante a um holograma, que é mostrado em uma tela na casa dos espelhos (ver Figura 2). Por meio desse processo, eles se replicam e ocorrem variações performativas, desestabilizando-os, mas também os fundindo entre si e com os visitantes. A 


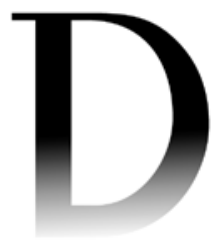

${ }^{15}$ Este e os dois parágrafos prévios foram publicados antes, em Carpentier (2019).

contingência democrática e as contradições mediadas da democracia tornam-se, igualmente, significadas e escritas nos corpos dos visitantes ${ }^{15}$.

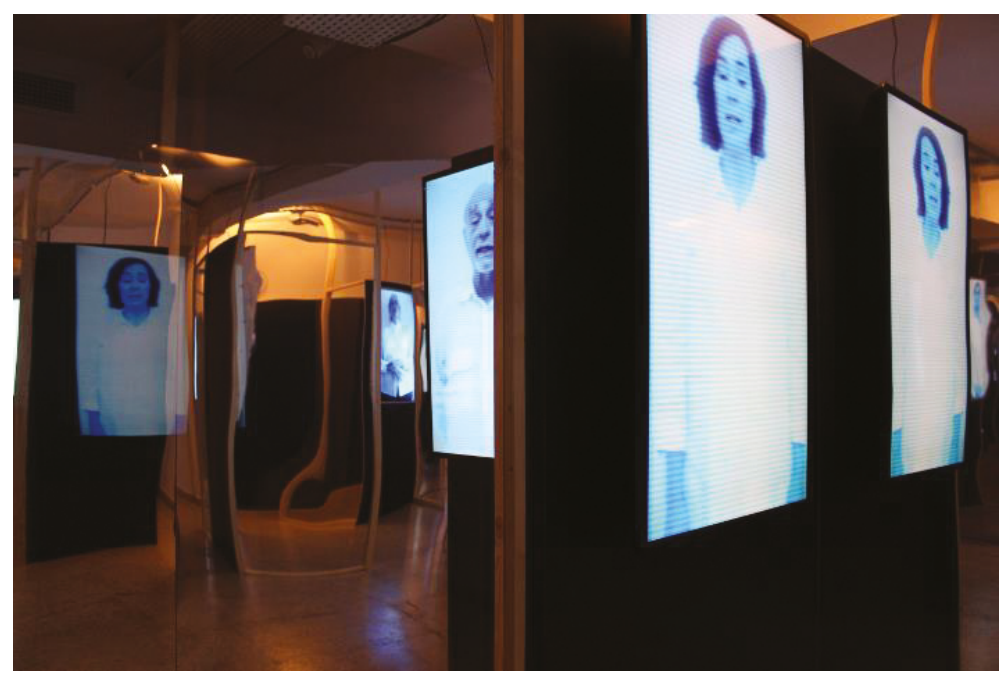

Figura 2

Foto do interior do Mirror Palace of Democracy

Nota. Foto do autor.

${ }^{16}$ Este termo também incorpora a antropologia/ sociologia visual, já que a multimodalidade agora é frequentemente usada também nesta abordagem. A antropologia/sociologia não é mencionada de maneira explícita por uma questão de síntese.

\section{COMUNICANDO E PRODUZINDO CONHECIMENTO NO/ATRAVÉS DO MIRROR PALACE OF DEMOCRACY}

A natureza experimental do $M P D$ e a raridade de experimentos desse tipo no campo dos estudos de mídia e comunicação (e no campo da teoria política, nesse caso) produzem, indiscutivelmente, a necessidade de refletir mais extensamente sobre o processo e o resultado desse projeto. Como experimento, o MPD foi inspirado pelas cinco abordagens discutidas na primeira parte deste artigo, mesmo sendo mais afiliado às abordagens de pesquisa acadêmicas multimodais e baseadas nas $\operatorname{artes}^{16} \mathrm{e}$ mais crítico em relação à abordagem de disseminação. Ao mesmo tempo, as iterações entre a revisão da literatura e a análise do $M P D$ também permitem o esclarecimento de algumas das dimensões-chave dessas cinco abordagens, ao mesmo tempo em que as utiliza para estruturar e apoiar as reflexões analíticas nessa parte do artigo. Metodologicamente, um procedimento autoetnográfico foi usado para embasar essa reflexão. Neste tipo de método de pesquisa qualitativa, "a (auto) experiência pessoal" é "sistematicamente analisada (graphy)" de modo compreender a "experiência cultural (etno)" (Ellis et al., 2010, para. 1). Nesse caso específico, a experiência pessoal corporificada, 
mas também a experiência entextualizada de construir o MPD forneceram a base para essa análise sistêmica.

O que o experimento demonstra, inicialmente, é a natureza integrada e iterativa dos diferentes componentes da produção de saber, em que a dimensão comunicativa não pode ser segregada de todo o processo de produção de conhecimento (ver Murray, 2009, p. 8). Nesse contexto, a iterabilidade ganha um significado bastante relacionado a seu significado metodológico (qualitativo) (Aspers \& Corte, 2019). Esse argumento já foi feito antes, também em relação à escrita acadêmica (ver, por exemplo, Bazerman, 1988), na qual o texto escrito enquanto ferramenta comunicativa é visto como solda do conhecimento e como as ideias são articuladas, comunicadas e lembradas exatamente. $\mathrm{O}$ reconhecimento da capacidade geradora de conhecimento das ferramentas comunicativas e a profunda implementação da comunicação do saber em todo o processo de produção do conhecimento não ficaram restritos, porém, ao texto escrito (W. Mitchell, 1994); além disso, o MPD demonstra a profunda correlação entre a produção de conhecimento e sua comunicação.

Em seu manifesto sobre multimodalidade, Wysocki et al. (2019, p. 19) argumentam que a "prática de criar" não está desconectada da "atividade crítica" ou, no caso particular do $M P D$, que a própria construção de uma instalação também (iterativamente) contribui para a formação de teoria. Eles escrevem,

Além disso, as práticas de criação e as atividades críticas devem se apoiar mutuamente. Tal perspectiva não privilegia um ou outro paradigma, mas os vê como as duas faces da mesma moeda: a análise informa a produção; a produção informa a análise. (p. 19)

De particular importância aqui é a capacidade gerativa das diferenças entre modos comunicativos diversos: lacunas de significação se abrem entre eles, oferecendo oportunidades de reconceitualização e rearticulação (Cope \& Kalantzis, 2009, p. 14).

A instalação do $M P D$, ao ser concebida e construída, produziu uma dinâmica própria e na/pela sua materialidade fez demandas quase autônomas para repensar e ampliar o quadro teórico. Na prática, muitas decisões operacionais tiveram de ser tomadas em sua construção, um processo com lógicas e serendipidades próprias, e algumas delas tiveram significativas repercussões teóricas. Alguns exemplos podem ilustrar isso: primeiro, as questões de segurança (do visitante) tornaram-se mais acentuadas quando um dos coordenadores do NeMe teve um encontro bastante desagradável com um dos painéis de acrílico transparente (pensando erroneamente que era uma saída). Nesse local foi, então, pouco antes 
da abertura da exposição, adicionada uma nota, alertando os visitantes que "correr contra os muros da democracia pode ser doloroso" (ver Figura 3). Isso, por sua vez, levou a uma ênfase no afeto que, até então, estava praticamente ausente do referencial teórico.

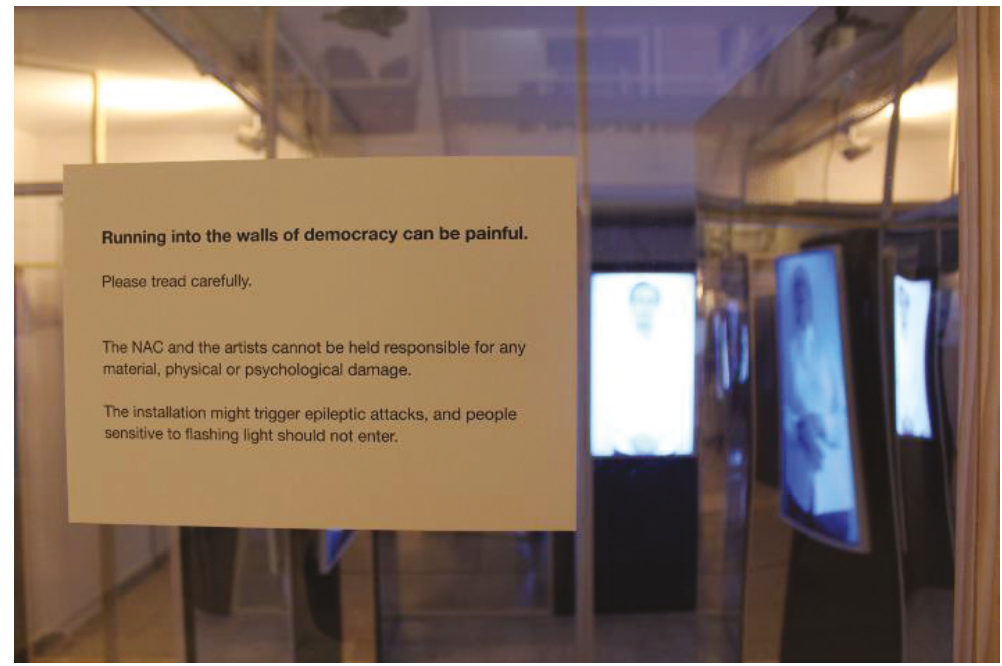

Figura 3

A anotação sobre a corrida contra as paredes

Nota. Foto do autor.

Mas a questão mais significativa (e insolúvel) derivada da construção material do $M P D$ foi sobre os limites da democracia. Era inevitável que o $M P D$, de formato quadrado, tivesse uma parte externa, a partir de suas paredes e das da galeria. Também deveria ter uma entrada e uma saída. A construção física do palácio de espelhos não só levantou a questão teórica sobre este exterior, mas também o que significava (teoricamente) a saída. A instalação foi construída no porão da galeria, permitindo que uma pequena escada em espiral fosse usada como saída, em referência à metáfora do vórtice (para cima) (ver Figura 4). Ainda mais contundente foi a etapa final da instalação, após o término da exposição, que consistiu na demolição da obra. Esse momento serviu como um lembrete sombrio de que a democracia pode acabar facilmente e se/quando isso ocorrer, será (muito provavelmente) pelas mãos de seus cidadãos. 


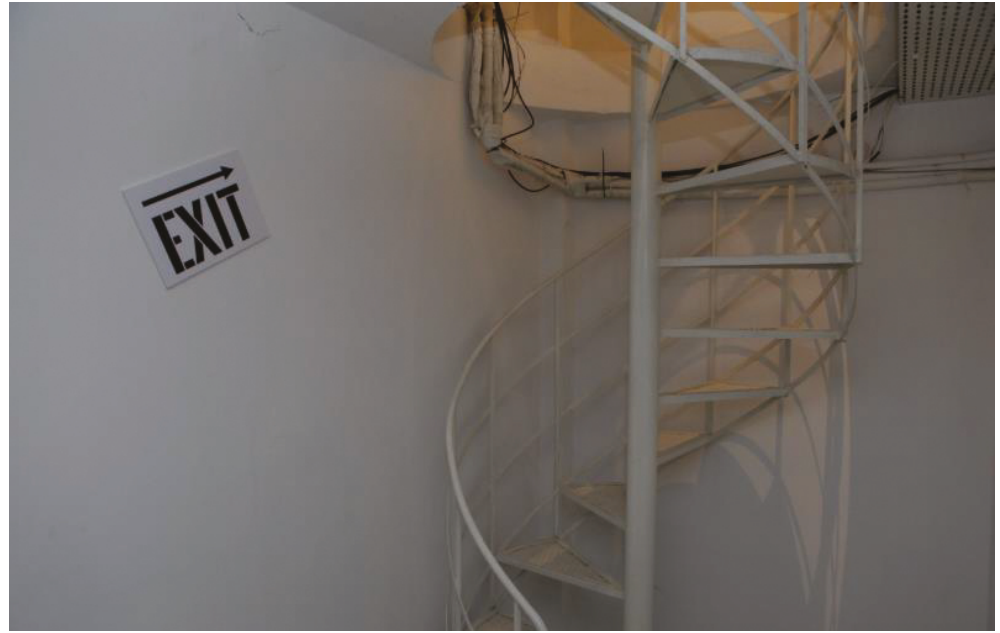

Figura 4

A escada de saída

Nota. Foto de Sakari Laurila, courtesia do NeMe.

Em segundo lugar, o experimento demonstra a complexidade e o hibridismo das posições de sujeito envolvidas. O trabalho de Cooperman (2018) sobre a pesquisa baseada nas artes exemplifica bem este ponto: "Escolhemos arriscar essa identidade como parte de desfazer os sistemas de poder que tão perfeitamente constroem e produzem quem e o que somos" (pp. 22-23). Criar um conjunto de repertórios artísticos e acadêmicos, teorias de democracia, representação e participação e componentes materiais que incluam madeira, painéis de acrílico e melamina, espelhos e telas de TV, no mínimo, complica a posição de sujeito do acadêmico. A autoria do $M P D$ demonstra como a posição de sujeito do acadêmico pode ser articulada com outras, como a posição de sujeito do artista, afetando ambas as posições de sujeito a partir do processo articulatório, sem anular a posição de sujeito do acadêmico.

Mesmo que as duas posições de sujeito compartilhem elementos (por exemplo, criatividade e intuição, como Janesick, 2001, argumenta), sua combinação explícita no que Sinner (2014) chama de "artedemia", na falta de um termo melhor ${ }^{17}$, tem uma série de implicações, o que também ficou evidente por meio da autoria do $M P D$. As práticas acadêmico-artísticas, como o MPD deixou claro, demonstram que ambas as posições de sujeito podem ser conciliadas e que, portanto, não são mutuamente exclusivas. Em outras palavras, é possível manter uma identificação com a posição de sujeito acadêmico, procurando a sistematicidade, um senso de precisão e abstração, um posicionamento ético e de transparência e a referencialidade
${ }^{17}$ Existem alternativas, no entanto. Finley (2008), por exemplo, refere-se a "artistas como pesquisadores/ pesquisadores como artistas" (p. 73), o que é um pouco longo para ser usado aqui. 


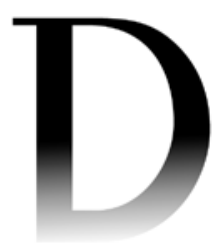

${ }^{18}$ Definida aqui como a conexão explícita a um corpo de conhecimento acadêmico.

${ }^{19}$ Apoio complementar foi fornecido pelo teatro estatal de Uppsala na Suécia (com seus atores Emil Brulin e Åsa Forsblad Morisse); pelos atores amadores Vaia Doudaki, Gary Gumpert e Annika Waern; e pela curadora assistente do Respublika! Olga Yegorova. dialógica ${ }^{18}$, em combinação com a utilização de repertórios artísticos que não conduzem à instrumentalização do artístico, mas, em vez disso, respeitam seu compromisso complexo com a estética, o senso de abstração, ética e referencialidade dialógica que também caracterizam as artes, embora de forma diferente. Além disso, essas práticas demonstram que essa conciliação é potencialmente benéfica, permitindo o enriquecimento de repertórios comunicativos acadêmicos e artísticos e o desenvolvimento de conhecimentos em geral. Terceiro, essas práticas demonstram que a academia não é o único local de produção de saber, mas que muitos campos diferentes da sociedade, incluindo as artes, também se envolvem na produção de conhecimento e que o mito de um centro singular de produção de saber não se sustenta. É, como Finley (2008) escreve, "um ato de rebelião contra a 'verdade' monolítica que a ciência supostamente carrega" (p. 73). E, por fim, o $M P D$, como forma de comunicação do conhecimento impulsionada por uma postura de sujeito híbrido acadêmico-artística, permitiu assumir mais o controle do processo comunicativo, diminuindo a dependência dos agentes do saber típicos da abordagem tradicional de disseminação do conhecimento. Isso torna o artista-acadêmico mais autônomo, evitando o que Fahnestock (1986) chama de “acomodações científicas".

Os parágrafos anteriores não pretendem sugerir que a reconciliação dessas posições de sujeito foi fácil. Em particular, há a questão das habilidades que fazem parte do desempenho de ambas as posições de sujeito, pois sua ausência pode perturbar a posição de sujeito híbrido do "artedêmico". Como CapousDesyllas e Morgaine (2018) escrevem em seu prefácio, "Alguns proponentes da [pesquisa baseada nas artes] enfatizam que é necessário que os pesquisadores desenvolvam as habilidades e técnicas necessárias à forma de arte escolhida para não parecerem amadores em seus esforços" (p. xii). Finley (2008), por exemplo, sugere formação para aqueles que não estão suficientemente familiarizados com a prática artística. $\mathrm{O}$ mesmo argumento pode ser feito para o componente acadêmico. Outras estratégias consistem na constituição de equipes colaborativas (Eisner, 2008), ou simplesmente serem menos exigentes, como, por exemplo, Leavy (2015), sugere: “[A Pesquisa baseada em artes] não é arte pela arte. É uma coisa diferente que é artística, mas não apenas artística” (p. 30). O experimento do $M P D$ demonstra que a criação de uma equipe de apoio ${ }^{19}$ - dois carpinteiros (ver Stavros Anastasiou trabalhando, na Figura 5); Yiannis Colakides, coordenador do centro de artes e arquiteto; e Siddharth Chadha, um assistente de produção com formação como cineasta comunitário - combinada com a especificidade da arte da instalação e com um "artedêmico" à vontade e conhecedor dessa forma de arte e da pesquisa acadêmica foi suficiente. 


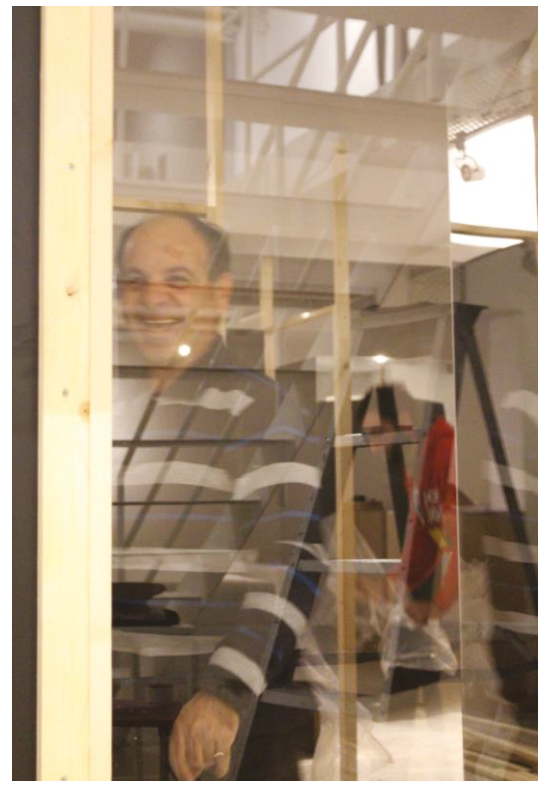

Figura 5

A etapa da construção, com o carpinteiro Stavros Anastasiou

Nota. Foto do autor.

Em terceiro lugar, o experimento mostra a possibilidade de projetos como o do MPD de atingir públicos diversificados. Uma parte considerável da literatura que trata das cinco abordagens expressa um otimismo significativo sobre a capacidade dos textos acadêmicos não escritos (ou textos escritos de forma diferente) de atingir públicos diferentes e/ou maiores. Por exemplo, Leavy (2015) escreve que "a virada para as formas artísticas de representação leva a pesquisa social para audiências e públicos mais amplos, mitigando alguns dos preconceitos educacionais e de classe social que tradicionalmente condicionam os beneficiários da investigação acadêmica" (p. 292). Literat e colegas (2018), escrevendo sobre pesquisa multimodal, utilizam uma argumentação semelhante, embora formulada com mais cautela. Eles escrevem que, "ao comunicar as conclusões da pesquisa em múltiplos modos e em várias plataformas, os acadêmicos podem ir além do público acadêmico tradicional" (p. 572). A acessibilidade do conteúdo é, para Literat et al., fundamental para alcançar essa abrangência ampliada, o que, por sua vez, oferece aos cidadãos a oportunidade de se envolver mais e melhor com os resultados da pesquisa.

Atingir um público maior e mais diversificado não é, entretanto, o único argumento usado neste contexto. Como mencionado na discussão da abordagem de troca de conhecimento, a participação na produção do saber - compartilhamento 


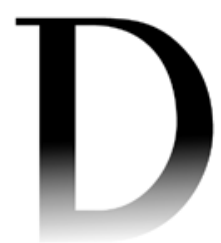

de conhecimento - também é articulada como resultado possível. Em seu artigo sobre pesquisa multimodal, Literat e colaboradores (2018), por exemplo, apontam para a capacidade de "cocriar conhecimento com os participantes da pesquisa" (p. 568). Em alguns casos, o argumento participativo é utilizado também em um sentido mais amplo, no qual são mencionadas as possibilidades de um reequilíbrio das relações de poder entre o campo acadêmico e outros campos da sociedade, abrindo não apenas espaços de produção compartilhada de conhecimento, mas também oportunidades para alcançar interpretações mais diversas (da comunicação do conhecimento), como Leavy (2015) argumenta ao escrever que "as obras de arte produzidas por pesquisa podem democratizar a construção de significado e descentralizar pesquisadores acadêmicos como 'os especialistas'” (p. 26).

O experimento do $M P D$ dá suporte parcial a essas vozes otimistas. Os cerca de 200 visitantes da exposição Respublika! Participation Matters claramente não eram exclusivamente acadêmicos, como testemunhado por meio de observações no local e entrevistas informais, combinadas com uma análise dos registros no livro de visitantes. Além disso, as 207 assistências únicas do filme $A$ visit to the Mirror Palace of Democracy no Vimeo (https://vimeo.com/249194905) e os 1.814 downloads do catálogo da Respublika! (até a data da escrita: $1^{\circ}$ de setembro de 2019) também dificilmente originam-se apenas de acadêmicos, mesmo se há falta de dados precisos. Mas, ao mesmo tempo, a galeria de arte, embora localizada no centro de uma grande cidade cipriota (Limassol) e sem taxa de entrada,

${ }^{20}$ Por esse motivo, vários eventos e performances da Respublika! foram realizados fora do NeMe Arts Center, mas o MPD foi montado no centro. ainda criava novas exclusões ${ }^{20}$. A utilização de repertórios artísticos abre espaços para públicos que não trabalham (ou estudam) em instituições acadêmicas; no entanto, as instituições de arte não são necessariamente acessíveis, de modo igualitários, a todos. Mesmo que isso diminua o entusiasmo de alguns proponentes de trabalhos de pesquisa multimodais e artísticos, não devemos esquecer que a ideia de um "público em geral", agrupando todos os não acadêmicos, é um mito inútil e que devemos pensar em termos de uma diversidade de públicos (ou grupos-alvo) com uma multiplicidade de características que só podem ser alcançadas de forma imperfeita por meio de uma diversidade de canais.

$\mathrm{O} M P D$ não correspondeu às altas expectativas no que diz respeito à produção participativa de conhecimento, de acordo com a abordagem da troca de conhecimento e em partes da abordagem da pesquisa baseada nas artes. Como seu criador, mantive firme controle do processo de concepção e construção (mesmo sendo auxiliado por um grupo de apoio). O MPD estava muito mais relacionado à arte interativa, oferecendo a "espectadores ativados" (Bishop, 2005, p. 102) oportunidades de imergir na obra de arte e vivenciar fisicamente 
a contingência da democracia ou, em outras palavras, ter uma experiência tangível de sua natureza ideologicamente cacofônica.

A obra de arte ainda requeria o corpo do visitante que entrava no palácio dos espelhos e tinha os vídeos inscritos em seu corpo. No entanto, mesmo que fosse interativo, ainda era um texto teórico altamente estruturado que explicitamente evitava ser muito aberto ou com excessiva leiturabilidade (Barthes, 1974, p. 4). Mesmo que os textos com escriturabilidade também estejam abertos à interpretação, tornar o MPD demasiadamente leiturável poderia encaminhá-lo para fora do domínio da comunicação da pesquisa acadêmica. Esta é, sem dúvida, uma das áreas nas quais a celebração da multiplicidade interpretativa e da abertura textual (Leavy, 2015, p. 26) precisa ser qualificada. Ainda assim, oferecer aos visitantes a oportunidade de vivenciar a contingência da democracia produziu efeitos de satisfação que dificilmente experimentei como autor de textos escritos. Além disso, ser capaz de guiar os visitantes por toda a exposição (como curador da Respublika!) e discutir suas experiências após a saída do MPD foi uma experiência única, altamente gratificante e agradável, que os autores de textos acadêmicos escritos dificilmente têm.

\section{CONCLUSÃO}

Tanto a visão geral das cinco abordagens - todas, a sua maneira, exigindo diversidade textual ao comunicar o conhecimento acadêmico - e o experimento do $M P D$ podem (e pretendem) ser lidos como convites para os acadêmicos dos estudos de mídia e da comunicação (e de outras áreas) complementarem o uso de textos acadêmicos escritos com modos alternativos de comunicação acadêmica. Vários campos fizeram progressos consideráveis ao utilizar esses modos ainda novos e oferecem boas razões para pelo menos se envolver em mais experimentos com a pesquisa acadêmica multimodal e baseada nas artes, para avaliá-los criticamente e aprender com eles e, então, considerar a inclusão esses modos alternativos em nossos repertórios comunicativos "regulares".

Isso (obviamente) não é um chamado para abandonar o texto escrito, que se provou vital na história centenária da investigação acadêmica. $O$ texto escrito tem recursos específicos que funcionam bem para a construção de teoria, argumentação e contra-argumentação, referencialidade e muito mais. É, por exemplo, uma decisão consciente descrever a análise autoetnográfica do $M P D$ em um texto acadêmico escrito, tornando visível uma experiência experimental criativa individual e adicionando uma camada de significado ao conjunto de reflexões por e sobre o MPD. Além disso, Jagodzinski e Wallin (2013, p. 21) descreveram a presente conjuntura como caracterizada pela pós-alfabetização, alertando para as 
consequências da redução do letramento. Indiscutivelmente, há uma necessidade crescente de letramentos e que estes se somem, não para menos; nessa perspectiva, há bons motivos para se precaver no sentido de evitar que os acadêmicos contribuam para uma lógica de substituição. Em outras palavras, o argumento de Murray (2009, p. 8) para adição e não substituição é mais válido do que nunca.

Ao mesmo tempo, como argumentei, os modos alternativos (artísticos) de comunicação têm algo a oferecer que é muito promissor para ser ignorado nos níveis de produção de conhecimento e sua comunicação, posições de sujeito híbrido e diversificação, interação e participação de públicos. Mas também aqui há motivos para ser cauteloso e evitar a celebração excessivamente entusiasmada desses modos alternativos de comunicação acadêmica. Dada a complexidade de reconfigurar o ambiente acadêmico, desenvolver a identidade do trabalho de posições de sujeito híbridas e adquirir e empregar os conjuntos de habilidades ampliadas necessárias, a pesquisa acadêmica multimodal e baseada na arte deve permanecer um convite e não se tornar uma obrigação. Mas, inversamente, quando os acadêmicos se envolvem nessas novas práticas, há uma necessidade de apreço e apoio institucional, muitas vezes também faltantes (Leavy, 2015, p. 266). Mesmo que ainda haja um longo caminho a percorrer - em particular, no campo dos estudos de mídia e comunicação - avançar cuidadosa e criticamente, criando uma massa crítica de acadêmicos dispostos a engajar-se em mais experimentos, eventualmente também permitirá enriquecer o campo. M

\section{AGRADECIMENTOS}

O Ministério da Educação e Cultura do Chipre, a Vrije Universiteit Brussel, a Uppsala Universitet, o Cyprus Community Media Centre, NeMe, Cost Action 18136, SQRIDGE e o Programa de Pesquisa em Comunicação Ambiental Mistra apoiaram este projeto e/ou publicação. Quero agradecer a Sakari Laurila e ao NeMe por me conceder permissão para usar uma das fotos de Laurila.

\section{REFERÊNCIAS}

Alter, N. (2018). Introduction. In N. Alter (Ed.), The essay film after fact and fiction (pp. 1-29). Columbia University Press.

Aspers, P., \& Corte, U. (2019). What is qualitative in qualitative research. Qualitative Sociology, 42(2), 139-160.

Barone, T. (2008). Creative nonfiction and social research. In J. G. Knowles \& A. Cole (Eds.), Handbook of the arts in qualitative research (pp. 105-115). SAGE Publications. 
Barthes, R. (1974). S/Z. Blackwell.

Bateson, G., \& Mead, M. (1942). Balinese character: A photographic analysis. New York Academy of Sciences.

Bazerman, C. (1988). Shaping written knowledge: The genre and activity of the experimental article in science. University of Wisconsin Press.

Bennett, W. (2012). The personalization of politics: Political identity, social media, and changing patterns of participation. The ANNALS of the American Academy of Political and Social Science, 644(1), 20-39. https:// doi.org/10.1177/0002716212451428

Bishop, C. (2005). Installation art: A critical history. Tate Publishing.

Blundell, T. (2017). Protein crystallography and drug discovery: Recollections of knowledge exchange between academia and industry. IUCrJ, 4, 308-321. https://doi.org/10.1107/S2052252517009241

Bryant, C. (2003). Does Australia need a more effective policy of science communication? International Journal of Parasitology, 33, 357-361. https://doi. org/10.1016/s0020-7519(03)00004-3

Burns, T., O'Connor, D. J., \& Stocklmayer, S. (2003). Science communication: A contemporary definition. Public Understanding of Science, 12, 183-202. https://doi.org/10.1177/09636625030122004

Capous-Desyllas, M., \& Morgaine, K. (2018). Preface. In M. Capous-Desyllas, \& $\mathrm{K}$. Morgaine (Eds.), Creating social change through creativity: Anti-oppressive arts-based research methodologies (pp. vii-xix). Palgrave Macmillan.

Carpentier, N. (2017). The discursive-material knot: Cyprus in conflict and community media participation. Peter Lang.

Carpentier, N. (Ed.). (2019). Respublika! Experiments in the performance of participation and democracy. NeMe.

Chaplin, E. (1994). Sociology and visual representation. Routledge.

Chapman, O., \& Sawchuk, K. (2015). Creation-as-research: Critical making in complex environments. RACAR: Revue d'art Canadienne/Canadian Art Review, 40(1), 49-52. https://doi.org/10.2307/24327426

Collins, S., Durington, M., \& Gill, H. (2017). Multimodality: An invitation. American Anthropologist, 119(1), 142-153. https://doi.org/10.1111/aman.12826

Cooperman, H. (2018). Listening through performance: Identity, embodiment, and arts-based research. In M. Capous-Desyllas, \& K. Morgaine (Eds.), Creating social change through creativity: Antioppressive arts-based research methodologies (pp. 19-35). Palgrave Macmillan.

Cope, B., \& Kalantzis, M. (2009). "Multiliteracies": New literacies, new learning. Pedagogies: An International Journal, 4(3), 1-30. https://doi. org/10.1080/15544800903076044 
DeLanda, M. (2006). A new philosophy of society: Assemblage theory and social complexity. Continuum.

Eisner, E. (2008). Art and knowledge. In J. G. Knowles, \& A. Cole (Eds.), Handbook of the arts in qualitative research (pp. 3-12). SAGE Publications.

Elkins, J. (Ed.). (2007). Visual practices across the university. Wilhelm Fink.

Ellis, C., Adams, T., \& Bochner, A. (2010). Autoethnography: An overview. Forum: Qualitative Sozialforschung/Forum: Qualitative Social Research, 12(1), art. 10. Retrieved from https://bit.ly/2R7MhbC

Fahnestock, J. (1986). Accommodating science: The rhetorical life of scientific facts. Written Communication, 3(3), 275-296. https://doi.org/10.1177/074 1088398015003006

Fals-Borda, O., \& Rahman, M. (1991). Action and knowledge: Breaking the monopoly with participative action research. Intermediate Technology/Apex.

Finley, S. (2008). Arts-based research. In J. G. Knowles, \& A. Cole (Eds.), Handbook of the arts in qualitative research (pp. 71-81). SAGE Publications.

Ford, B. (1992). Images of science: A history of scientific illustration. British Library. Freeman, M. (2016). Approaching knowledge exchange. In M. Freeman (Ed.), Industrial approaches to media: A methodological gateway to industry studies (pp. 153-174). Palgrave Macmillan.

Gibbs, A. (2003). Writing and the flesh of others. Australian Feminist Studies, 18(42), 309-319. https://doi.org/10.1080/0816464032000171403

Gibson, J. (1979). The ecological approach to visual perception. Psychology Press.

Grady, J. (1996). The scope of visual sociology. Visual Sociology, 11(2), 10-24. https://doi.org/10.1080/14725869608583762

Guattari, F. (1993). Machinic heterogenesis. In V. Conley (Ed.), Rethinking technologies (pp. 13-27). University of Minnesota Press.

Gutberlet, J., Oliveira, B. J., \& Tremblay, C. (2017). Arts-based and participatory action research with recycling cooperatives. In L. Rowell, C. Bruce, J. Shosh, \& M. Riel (Eds.), The Palgrave international handbook of action research (pp. 699-715). Palgrave Macmillan.

Haas, G. (2017). Fictocritical strategies: Subverting textual practices of meaning, other, and self-formation. Transcript Verlag.

Henderson, L., Hogan, M., Christian, A., \& Erni, J. (2018). A dossier on making and doing. In A. Shaw \& D. T. Scott (Eds.), Interventions: Communication research and practice (pp. 273-284). Peter Lang.

Hockings, P. (Ed.). (1995). Principles of visual anthropology (2a ed.). de Gruyter. Holm, G. (2008). Visual research methods: Where are we and where are we going? In S. Nagy Hesse-Biber, \& P. Leavy (Eds.), Handbook of emergent methods (pp. 325-342). Guilford Press. 
Ivanič, R. (1998). Writing and identity: The discoursal construction of identity in academic writing. John Benjamins.

Jagodzinski, J., \& Wallin, J. (2013). Arts-based research: A critique and a proposal. Sense Publishers.

Janesick, V. (2001). Intuition and creativity: A pas de deux for qualitative researchers. Qualitative Inquiry, 7(5), 531-540. https://doi. org/10.1177/107780040100700501

Jarldorn, M. (2019). Photovoice handbook for social workers: Method, practicalities and possibilities for social change. Palgrave Macmillan.

Kara, H. (2015). Creative research methods in the social sciences: A practical guide. Polity Press.

Khadka, S., \& Lee, J. (Eds.). (2019). Bridging the multimodal gap: From theory to practice. Utah State University Press.

Klein, J. (2017, 23 de abril). What is artistic research? Journal for Artistic Research. Retrieved from https://www.jar-online.net/what-artistic-research

Kress, G., \& Van Leeuwen, T. (2001). Multimodal discourse: The modes and media of contemporary communication. Arnold.

Laclau, E., \& Mouffe, C. (1985). Hegemony and socialist strategy: Towards a radical democratic politics. Verso.

Lapum, J. (2018). Installation art: The voyage never ends. In P. Leavy (Ed.), Handbook of arts-based research (pp. 377-395). Guilford Press.

Leavy, P. (2011). Low-fat love. Sense Publishers.

Leavy, P. (2015). Method meets art: Arts-based research practice (2a ed.). Guilford Press. Lemke, J. (1998). Multiplying meaning: Visual and verbal semiotics in scientific text. In J. Martin, \& R. Veel (Eds.), Reading science: Critical and functional perspectives on discourses of science (pp. 87-113). Routledge.

Lewis, J. (2008). Cultural studies: The basics (2a ed.). SAGE Publications.

Literat, I., Conover, A., Herbert-Wasson, E., Page, K., Riina-Ferrie, J., Stephens, R., Thanapornsangsuth, S, \& Vasudevan, L. (2018). Toward multimodal inquiry: Opportunities, challenges and implications of multimodality for research and scholarship. Higher Education Research \& Development, 37(3), 565-578. https://doi.org/10.1080/07294360.2017.1389857

Loveless, N. (2015). Towards a manifesto on research-creation. RACAR: Revue dart Canadienne/Canadian Art Review, 40(1), https://doi.org/52-54. 10.2307/24327427

Lutkewitte, C. (2013). Multimodal composition: A critical sourcebook. Bedford/ St. Martin's.

Matschke, C., Moskaliuk, J., \& Cress, U. (2012). Knowledge exchange using Web 2.0 technologies in NGOs. Journal of Knowledge Management, 16(1), 159-176. https://doi.org/10.1108/dlo.2012.08126daa.010 
McPherson, T. (2009). Introduction: Media studies and the digital humanities. Cinema Journal, 48(2), 119-123.

Mead, M. (1995). Visual anthropology in a discipline of words. In P. Hockings (Ed.), Principles of visual anthropology ( $2^{\mathrm{a}}$ ed., pp. 3-10). de Gruyter.

Meyer, M. (2010). The rise of the knowledge broker. Science Communication, 32(1), 118-127. https://doi.org/10.1177/1075547009359797

Mitchell, H. (2006). Knowledge sharing: The value of storytelling. International Journal of Organisational Behaviour, 9(5), 632-641.

Mitchell, W. (1994). Picture theory: Essays on verbal and visual representation. University of Chicago Press.

Moncaster, A., Hinds, D., Cruickshank, H., Guthrie, P., Crishna, N., Baker, Beckmann, K., \& Jowitt, P. W. (2010). Knowledge exchange between academia and industry. Proceedings of the Institution of Civil Engineers - Engineering Sustainability, 163(3), 167-174. https://doi.org/10.1680/ensu.2010.163.3.167

Mouffe, C. (2005). On the political. Routledge.

Müllerleile, A. (2014). European studies and public engagement: A conceptual toolbox. Journal of Contemporary European Research, 10(4), 505-517. Retrieved form https://bit.ly/3bCNkcO

Murdock, A., Shariff, R., \& Wilding, K. (2013). Knowledge exchange between academia and the third sector. Evidence \& Policy, 9(3), 419-430. https:// doi.org/10.1332/174426413X671086

Murray, J. (2009). Non-discursive rhetoric: Image and affect in multimodal composition. State University of New York Press.

Norman, D. (1988). The design of everyday things. Basic Books.

Pink, S. (2004). Introduction: Situating visual research. In S. Pink, L. Kürti, \& A. Afonso (Eds.), Working images: Visual research and representation in ethnography (pp. 1-10). Routledge.

Reason, P., \& Bradbury, H. (2001). Handbook of action research: Participative inquiry and practice. SAGE Publications.

Reid, G., Snead, R., Pettiway, K., \& Simoneaux, B. (2016). Multimodal communication in the university: Surveying faculty across disciplines. Across the Disciplines: A Journal of Language, Learning and Academic Writing, 3(1). 1-29. Retrieved from https://bit.ly/3bDtC0A

Routledge, P. (1996). The third space as critical engagement. Antipode, 28(4), 399-419. https://doi.org/10.1111/j.1467-8330.1996.tb00533.x

Saldaña, J. (Ed.). (2005). Ethnodrama: An anthology of reality theatre. AltaMira Press.

Saldaña, J. (2011). Ethnotheatre: Research from page to stage. Left Coast Press. 
Selfe, C. (Ed.). (2007). Multimodal composition: Resources for teachers. Hampton Press.

Shipka, J. (2011). Toward a composition made whole. University of Pittsburgh Press. Sinner, A. (2014). Flight of the "artademics": Scholarly gentrification and conceptual+art discourses. Visual Arts Research, 40(1), 124-126. https://doi. org/10.1111/10.5406/visuartsrese.40.1.0124

Takayoshi, P., \& Selfe, C. (2007). Thinking about multimodality. In C. Selfe (Ed.), Multimodal composition: Resources for teachers (pp. 1-12). Hampton Press.

Thorndike-Breeze, R., Block, A., \& Brown, K. (2019). Entering the multiverse: Using comics to experiment with multimodality, multigenres and multiliteracies. In S. Khadka, \& J. Lee (Eds.), Bridging the multimodal gap: From theory to practice (pp. 159-181). Utah State University Press.

Trench, B., \& Bucchi, M. (2010). Science communication: An emerging discipline. Journal of Science Communication, 9(3), C03. https://doi. org/10.22323/2.09030303

Tyler, S. (1986). Post-modern ethnography: From document of the occult to occult document. In J. Clifford, \& G. Marcus (Eds.), Writing culture: The poetics and politics of ethnography (pp. 122-140). University of California Press.

Unicef. (2015). Knowledge exchange toolbox: Group methods for sharing, discovery and co-creation.

Veneti, A., Jackson, D., \& Lilleker, D. (Eds.). (2019). Visual political communication. Palgrave Macmillan.

Wysocki, R., Udelson, J., Ray, C., Newman, J., Matravers, L., Kumari, A., Gordon, L. M. P., Scott, K. L., Day, M., Baumann, Alvarez, S. A., \& DeVoss, N. (2019). On multimodality: A manifesto. In S. Khadka, \& J. Lee (Eds.), Bridging the multimodal gap: From theory to practice (pp. 17-29). Utah State University Press.

Artigo recebido em 31 de agosto e aprovado em 20 de setembro de 2020. 